\title{
Gender Issues in Achievement and Retention among Secondary School Students Taught Thermal Energy Using Metacognitive Scaffolding Teaching Strategy
}

\author{
P.A. Agu* and C.0. Iyamu \\ Faculty of Education, Nasarawa State University, Keffi, Nigeria \\ E-mail: Ashlameagu@yahoo.com; Caesariyamu71@Gmail.Com \\ *Corresponding author details: Assoc. Prof. P.A. Agu, Ashlameagu@yahoo.com
}

\section{ABSTRACT}

This study investigated gender issues in achievement and retention among secondary school students taught thermal energy using metacognitive scaffolding teaching strategy in Federal Capital Territory (FCT), Abuja, Nigeria. Four research questions were asked, while four null hypotheses were tested at 0.05 level of significance. Quasi experimental research design involving non-randomized control pretestposttest design was utilized. The study population consisted of 2699 Senior Secondary II (SSII) physics students from 54 public SSII physics students in FCT, Abuja. Multistage random sampling technique was used to select two schools for the study. From the two schools, two intact SSII classes were selected consisting of 75 SSII physics students. The instrument used for data collection consists of Thermal Energy Achievement Test (TEAT). The data collected from the instrument were analyzed using Statistical Package for Social Science (SPSS). The research questions were answered using mean and standard deviation while the null hypotheses were tested using Analysis of Covariance (ANCOVA). Findings from the analyzed data showed that physics students taught using metacognitive scaffolding teaching strategy performed better in their achievement scores than those taught using conventional lecture method; Male physics students did not perform better than their female counterpart when taught using metacognitive scaffolding teaching strategy; Physics students taught using metacognitive scaffolding teaching strategy performed better in their retention scores than their counterparts in the control group; Male physics students did not perform better in their retention scores than their female counterpart when taught using metacognitive scaffolding teaching strategy. Based on these findings, it was recommended among others that physics teachers should be encouraged to teach using metacognitive scaffolding teaching strategy. Government and educational agencies, curriculum planners and developers should encourage the training of physics teachers on metacognitive scaffolding teaching during seminars, workshops and conferences.

Keywords: gender; metacognitive scaffolding teaching strategy; physics, thermal energy; achievement; retention

\section{INTRODUCTION}

Scientific knowledge contains several bodies of knowledge of the natural world. These bodies of knowledge are embedded in science subjects consisting of physics, chemistry and biology. Physics as a body of science knowledge is concerned with matter and energy and the relationship between them (Okeke, Okeke \& Akande, 2008). The knowledge acquired from the study of physics is applied in the field agriculture, automobile, water supply, irrigation, civil works, electrical and electronics. Many inventions emanating from these fields which require the knowledge of physics for their understanding consist of electric kettle, petrol engine, diesel engine, jet engine, clinical thermometer, electric bulbs, X-ray machine, camera, car, radio, computer, television, batteries, electricity, speakers, military hardware, refrigerator and air conditioning.

Thermal energy is a branch of physics that deals with thermodynamic quantities such as heat and temperature, energy transfer which are associated with matter in physics. Energy transfer is associated with conduction, convention and radiation. The application of thermodynamics is useful to mechanical heat energy and chemical compound reactions, despite the benefits of physics to the society student's achievement in the subject remains low. Physics students' achievement at Senior Secondary Certificate Examination (SSCE) in Nigeria has been low over the years (Saage, 2009). Statistics of students' achievement in May/June West African Senior Secondary Certificate Examination (WASSCE) Physics examination from 2010 to 2017 shows that students' achievement in physics has been low over the years.

TABLE 1: Students' Achievement in May/June20102017 WASSCE Physics in Nigeria

\begin{tabular}{|c|c|c|c|c|}
\hline \multirow{2}{*}{$\begin{array}{c}\text { Total } \\
\text { Entry }\end{array}$} & \multicolumn{2}{|c|}{ Pass Grade Levels } & \multicolumn{2}{c|}{ Fail Grade Levels } \\
\cline { 2 - 5 } & (A1-C6) & $\mathbf{\%}$ & (D7-F9) & \% \\
\hline 387,380 & 148,599 & $38.36 \%$ & 238,781 & $61.64 \%$ \\
\hline 374,958 & 162,769 & $43.41 \%$ & 212,189 & $56.59 \%$ \\
\hline 386,449 & 190,210 & $49.22 \%$ & 196,239 & $50.78 \%$ \\
\hline 423,146 & 153,137 & $36.19 \%$ & 270,009 & $63.81 \%$ \\
\hline 402,228 & 140,056 & $34.82 \%$ & 262,172 & $65.18 \%$ \\
\hline 398,870 & 145,747 & $36.54 \%$ & 253,123 & $63.46 \%$ \\
\hline 416,580 & 174,432 & $41.9 \%$ & 242,148 & $58.1 \%$ \\
\hline 422,110 & 183,020 & $43.4 \%$ & 239,090 & $56.6 \%$ \\
\hline
\end{tabular}

Source: West African Examinations Council (2017) 
Physics students' achievement at SSCE has been dwindling over the years. In some years, failure rate in physics is as high as 65\%. WAEC (2017) showed that the general results of students that wrote May/June WASSCE Physics examination from 2010 to 2017 had a failure rate above $50 \%$. Low achievement in physics at SSCE is reported to be attributed to difficult topics in physics including thermal energy (Mustafa, 2006). The reasons why most physics students fail thermal energy may be because it contains mathematical concepts and models which require background knowledge of mathematical principles to solve them. Therefore, physics' students find it difficult to understand thermal energy due to their poor knowledge of mathematics. Apart from the problem of mathematical physics task, the lack of the use of modeling to demonstrate experiment in the class may also affect students' cognition and achievement.

In order to ensure that students' excel in thermal energy, over dependent on the use of conventional lecture method by teachers should be minimized. Wood and Gentile (2003) opined that in conventional teaching method, there are no teacher-students interactions as the teacher dominates all the class activities right from the beginning of the lesson to the end. Conventional lecture method also has the attributes of brief teaching, which hinders collaborative thinking that promotes reflection and metacognition. Many researchers have opined that conventional teaching method may cause students to resort to rote learning and memorization instead of reflective thinking that is more effective in enhancing their cognition (Nworgu, 2012). Rote learning hinders students' thinking initiatives during class activities and also prevents them from fully exploring and understanding complex principles in thermal energy. Duyilemi, Olangunju and Olumide (2014) remarked that overreliance on conventional teaching methods in the teaching of physics may affect students' achievement in the subject.

Agommuoh and Ifeanacho (2013) pointed out that for teaching to be effective in impacting on students' achievement and retention, the minds of students need to be exposed to varieties of innovative teaching and learning activities that would stimulate students' mental thinking to develop their own cognition. There are varieties of innovative teaching strategies that enhance mental thinking skills and among them is metacognitive scaffolding teaching strategy. Metacognitive scaffolding teaching strategy is a teaching strategy that emanated from the word-scaffolding in the field of construction. Scaffolding is used as a support structure that assists construction workers to execute difficult task. Typical scaffolding consists of tightly fitted horizontal, vertical and diagonal members that are either made of wood or steel materials to form a rigid structural framework. In the field of education, these scaffolding members are refers to as teaching models used to assist students solve difficult task beyond their dependent abilities (Wolf, 2003). These teaching models when used to develop students' mental thinking abilities to a higher one that would promote their self-cognition, it is referred to as metacognitive scaffolding teaching strategy. The term metacognitive scaffolding teaching strategy emanated from the concept of metacognition which refers to the cognitive functioning of a person. This cognitive functioning involves series of mental thinking processes involved in knowledge internalization in a learner (Nodoushan, 2008 \& Freeman, 2013). Therefore, metacognitive scaffolding teaching strategy can be defined as a teaching framework that utilizes several innovative teaching models used to assist students attain a mental thinking level where they can develop their own cognition needed to solve difficult tasks. In order to achieve the effect of metacognitive scaffolding teaching strategy several scaffolds models are planned in order to make the teaching of difficult topics easier. These scaffolds according to Many (2002), Denton (2014) and Hall (2015) may include advanced organizer, modeling, worked examples, explicit and problem solving approach, concept/mind maps, instructing, prompts, hints and questioning.

In this study, three teaching models were used in metacognitive scaffolding teaching strategy, the experiment lessons in thermal energy were taught using modeling teaching strategy while mathematical physics lessons were taught using explicit mathematics/problem solving strategy. Advanced organizer was used to introduce physics concepts in thermal energy and then linked to students' prior knowledge. During teaching using modeling and explicit mathematics/problem solving models, the teacher used think aloud and questioning techniques while during problem solving, the teacher further assisted physics students using cueing and hints strategies.

Achievement in this study refers to students' scores in a test/examination. Students that have the required grade in an examination were classified as high achievers while students that failed to reach the required grade in an examination were classified as low achievers. The reason for relating metacognitive scaffolding teaching strategy with achievement is that students who had low grade in physics due to their inability to solve difficult questions may get their thinking abilities improved to enable them understand and solve difficult tasks. Metacognitive scaffolding teaching strategy also encourages collaborative thinking between teacher and learners which could enable learners develop their mental thinking to understand difficult topics and tasks. When students are able to solve difficult tasks, their achievement in physics may be enhanced.

Retention is the ability to keep things in memory (Merriam-Webster Dictionary, 2006). It can also be referred to as the mental thinking strength of students to remember what they have learnt after a period of time. Lindstrom and Sharma (2011) emphasized that human memory is large enough to store knowledge for remembrance and the storage capacity may be limited when students do not understand and can recall what they were taught. In order to understand and retrieve what has been learnt after a period of time, students have to think through what they have learnt in order to internalize it in their mind. Therefore, metacognitive scaffolding teaching strategy may help improve student's retention by creating an interactive atmosphere for creative and reflective thinking that enable knowledge to be stored inside the mind of students through thinking. This stored knowledge enables students gain mastery and retain knowledge. Omwirhiren (2015) opined that retention may be limited by the use of conventional teaching methods in physics and this could be the cause of students' low achievement in the SSCE.

Gender effect on students' achievement and retention is sometimes attributed to the discrimination problem of gender inequality in the society. In the home front female for example, children are mostly used for domestic works. This creates boredom and lack of concentration in the class. Apart from the stress condition faced by female students at home, Abosede (2010) opined that male dominance in science subjects could be adduced to cultural and social orientation from parents and the society. Most parents prefer their female children to study art and social 
science rather than technical or science courses. This male dominance is seen in general classroom interactions (Katcha \& Yabogi, 2015). This may affect female students' academic achievement in science and technology and their attitude towards courses including physics (Bello \& Oluwatosin, 2014). This contention is also supported by the outcome of Uzoechi and Gimba (2015) who found out that males performed better than females in physics. Some findings into the effect of metacognitive scaffolding teaching strategy in certain subjects showed that it has a positive effect on students' learning outcome (Azevedo \& Hadwin, 2005). James and Okpala (2010) also found that metacognitive scaffolding teaching strategy had significant effect on students' literacy skills in reading comprehension. Metacognitive scaffolding teaching strategy has also been reported to be effective in solving difficult tasks in design problem solving and analytical skills in other subject areas, but not many studies have reported its effect in physics. It is in view of this, that this study investigated the effect of metacognitive scaffolding teaching strategy on senior secondary physics students' achievement and retention in thermal energy in Federal Capital Territory, Abuja, Nigeria.

\section{RESEARCH QUESTIONS}

i. What are the mean achievement scores of physics students taught thermal energy using metacognitive scaffolding teaching strategy and those taught using conventional lecture method?

ii. What are the mean achievement scores of male and female physics students taught thermal energy using metacognitive scaffolding teaching strategy?

iii. What are the mean retention scores of physics students towards thermal energy taught using metacognitive scaffolding teaching strategy and those taught using conventional lecture method?

iv. What are the mean retention scores of male and female physics students taught thermal energy using metacognitive scaffolding teaching strategy?

\section{HYPOTHESES}

The following null hypotheses were tested in the study.

Ho1: There is no significant difference in the mean achievement scores of physics students taught thermal energy using metacognitive scaffolding teaching strategy and those taught using conventional lecture method.

Ho2: There is no significant difference in the mean achievement scores of male and female physics students taught thermal energy using metacognitive scaffolding teaching strategy.

Ho3: There is no significant difference in the mean retention scores of physics students towards thermal energy taught using metacognitive scaffolding teaching strategy and those taught using conventional lecture method.

H04: There is no significant difference in the mean retention scores of male and female physics students taught thermal energy using metacognitive scaffolding teaching strategy.

\section{METHODOLOGY}

Quasi-experimental research design involving non randomized control group pretest-posttest design was used as the research design for the study. It employed non- randomized control group pretest-posttest design deals with the use of intact classes. The population of the study consisted of 2699 SSSII physics students (1609 male and 1090 female) from 54 Senior Secondary Schools that are public and co-educational in Federal Capital Territory (FCT), Abuja. A sample size of 75 SSII physics students from two intact physics classes (40 and 35 physics students) were selected out of a population of 2699 SSII physics students in FCT-Abuja using multistage random sampling. Two intact classes from two senior secondary two (SSII) offering physics were randomly assigned to control and experimental groups. Before the treatment was carried out, pretest was given to the schools in the study area from which two schools with most similar means were selected. The two schools were then randomly assigned to the experimental and control groups. Thereafter, the control and experimental groups were exposed to metacognitive scaffolding teaching strategy and conventional teaching method respectively for a period of 8 weeks. After 8 weeks, posttest which contains the same questions as the pretest was administered to the two sampled schools after the treatment. The pretest questions were reshuffled as retention test and administered after 4 weeks.

The instrument for data collection consists of Thermal Energy Achievement Test (TEAT). The TEAT was used to measure physics students' achievement in thermal energy. The questions were adapted from SSCE past questions and contains questions on temperature and its measurement, thermometer, absolute scale of temperature, specific heat capacity, latent heat capacity, evaporation, boiling and sublimation and relative humidity and dew points.

The TEAT was given to two science education experts and one measurement and evaluation expert for validation. The reliability of TEAT was determined by trial testing Government Secondary School (GSS) 2, Jikwoyi in FCTAbuja. The data collected were analyzed using KuderRichardson $(\mathrm{K}-\mathrm{R})_{21}$ to obtain a reliability coefficients of 0.92. Physics students in the experiment group were taught using metacognitive scaffolding teaching strategy, while physics students in the control group were taught using conventional teaching method. Both groups were taught for eight weeks. At the end of the eight weeks, TEAT was administered as posttest to physics students in the two groups. After four weeks TEAT was administered as Thermal Energy Retention Test (TERT). The data collected from the instruments were analyzed using Statistical Package for Social Science (SPSS) model. The research questions were answered using mean and standard deviation, while the hypotheses were tested using Analysis of Covariance (ANCOVA) at 0.05 level of significance.

\section{RESULT}

\section{Research Question 1}

What are the mean achievement scores of physics students taught thermal energy using metacognitive scaffolding teaching strategy and those taught using conventional teaching method?

TABLE 2: Means and Standard Deviations of Achievement Scores of Physics Students Taught Using Metacognitive Scaffolding Teaching Strategy and Conventional Teaching Method 


\begin{tabular}{|c|c|c|c|c|c|c|}
\hline Groups & Tests & N & Mean & SD & $\begin{array}{c}\text { Relative } \\
\text { SD }\end{array}$ & $\begin{array}{c}\text { Standard } \\
\text { Error }\end{array}$ \\
\hline \multirow{2}{*}{ Treatment } & Pretest & 30 & 23.55 & 6.36 & 0.23 & 1.34 \\
\cline { 2 - 7 } & Posttest & 30 & 26.30 & 8.51 & 0.32 & 1.55 \\
\hline \multirow{2}{*}{ Control } & Pretest & 36 & 20.19 & 9.76 & 0.57 & 1.78 \\
\cline { 2 - 7 } & Posttest & 36 & 21.25 & 10.06 & 0.47 & 1.68 \\
\hline
\end{tabular}

Table 2 indicates that the mean achievement scores of physics students in the treatment group were higher than the mean achievement scores of their control group counterparts. The relative standard deviations of the treatment group were lower than their control group counterpart. This shows that the control group had physics scores that are more widespread and in agreement with the mean than the treatment group.

\section{Research Question 2}

What are the mean achievement scores of male and female physics students taught thermal energy using metacognitive scaffolding teaching strategy?

In answering this question, data obtained from TEAT from the treatment group was used. The pretest, posttest mean scores and standard deviation of male and female physics students from the treatment group were analyzed and compared. Summary of result of data analysis is presented in Table 3 .

TABLE 3: Means and Standard Deviations of Achievement Scores of Male and Female Physics Students Taught Using Metacognitive Scaffolding Teaching Strategy

\begin{tabular}{|c|c|c|c|c|c|c|}
\hline Groups & Tests & $\mathbf{N}$ & Mean & SD & $\begin{array}{c}\text { Relative } \\
\text { SD }\end{array}$ & $\begin{array}{c}\text { Standard } \\
\text { Error }\end{array}$ \\
\hline \multirow{2}{*}{ Male } & Pretest & 47 & 26.73 & 8.228 & 0.346 & 1.345 \\
\cline { 2 - 7 } & Posttest & 47 & 23.87 & 9.622 & 0.403 & 1.404 \\
\hline \multirow{2}{*}{ Female } & Pretest & 19 & 21.81 & 9.432 & 0.457 & 2.174 \\
\cline { 2 - 7 } & Posttest & 19 & 22.74 & 9.955 & 0.448 & 2.284 \\
\hline
\end{tabular}

Table 3 indicates that the mean achievement score of male physics students were higher than the mean achievement score of female physics students. The relative standard deviations of the male physics students were higher than their female counterpart. This shows that the female physics students had physics scores that are more widespread and in agreement with the mean than their male counterpart.

\section{Research Question 3}

What are the mean retention scores of physics students taught thermal energy using metacognitive scaffolding teaching strategy and those taught using conventional teaching method?

In answering this question, data obtained from TERT from the treatment and control groups were used. The pretest, retention mean scores and standard deviation from the treatment and control groups were analyzed and compared. Summary of result of data analysis is presented in Table 4.

TABLE 4: Means and Standard Deviations of Retention Scores of Physics Students Taught Using Metacognitive Scaffolding Teaching Strategy and Conventional Teaching Method

\begin{tabular}{|c|c|c|c|c|c|c|}
\hline Groups & Tests & N & Mean & SD & $\begin{array}{c}\text { Relative } \\
\text { SD }\end{array}$ & $\begin{array}{c}\text { Standard } \\
\text { Error }\end{array}$ \\
\hline \multirow{2}{*}{ Treatment } & Pretest & 30 & 25.47 & 7.65 & 0.30 & 1.33 \\
\cline { 2 - 7 } & Retention & 30 & 27.87 & 7.79 & 0.28 & 1.42 \\
\hline \multirow{2}{*}{ Control } & Pretest & 36 & 21.23 & 9.88 & 0.47 & 1.68 \\
\cline { 2 - 7 } & Retention & 36 & 20.36 & 9.98 & 0.49 & 1.66 \\
\hline
\end{tabular}

Table 4 shows that the mean retention score of physics students in the treatment group were higher than the mean retention score of physics students in the control group. The relative standard deviations of the control group were higher than that of the treatment group. This shows that the control group had physics scores that are more widespread and in agreement with the mean than the treatment group.

\section{Research Question 4}

What are the mean retention scores of male and female physics students taught thermal energy using metacognitive scaffolding teaching strategy?

In answering this question, data obtained from TERT from the treatment group was used. The pretest, retention mean scores and standard deviation of male and female physics students from the treatment group were analyzed and compared. Summary of result of data analysis is presented in Table 5.

TABLE 5: Means and Standard Deviations of Retention Scores of Male and Female Physics Students Taught Using Metacognitive Scaffolding Teaching Strategy

\begin{tabular}{|c|c|c|c|c|c|c|}
\hline Groups & Tests & $\mathbf{N}$ & Mean & SD & $\begin{array}{c}\text { Relative } \\
\text { SD }\end{array}$ & $\begin{array}{c}\text { Standard } \\
\text { Error }\end{array}$ \\
\hline \multirow{2}{*}{ Male } & Pretest & 47 & 23.37 & 9.68 & 0.31 & 1.41 \\
\cline { 2 - 7 } & Retention & 47 & 24.49 & 9.76 & 0.40 & 1.42 \\
\hline \multirow{2}{*}{ Female } & Pretest & 19 & 21.87 & 9.65 & 0.43 & 2.13 \\
\cline { 2 - 7 } & Retention & 19 & 22.00 & 9.71 & 0.44 & 2.23 \\
\hline
\end{tabular}

Table 5 indicates that the mean retention score of male physics students were higher than the mean retention score of female physics students. The relative standard deviations of female physics students were higher than their male physics students. This shows that the female physics students had physics scores that are more widespread and in agreement with the mean than their male counterpart.

Hypothesis 1: There is no significant difference in the mean achievement scores of physics students taught thermal energy using metacognitive scaffolding teaching strategy and those taught using conventional teaching method. 
TABLE 6: ANCOVA Analysis of the Mean Achievement Scores of Physics Students taught Using Metacognitive Scaffolding Teaching Strategy and Conventional Teaching Method

\begin{tabular}{|l|l|l|l|l|l|}
\hline \multicolumn{1}{|c|}{ Source } & $\begin{array}{c}\text { Type III } \\
\text { Sum of } \\
\text { Squares }\end{array}$ & df & Mean Square & F & Sig. \\
\hline $\begin{array}{l}\text { Corrected } \\
\text { Model }\end{array}$ & $4939.977^{\mathrm{a}}$ & 2 & 2469.988 & 138.889 & .000 \\
\hline Intercept & 803.357 & 1 & 803.357 & 45.173 & .000 \\
\hline Pretest & 4522.663 & 1 & 4522.663 & 254.312 & .000 \\
\hline Group & 370.555 & 1 & 370.555 & 20.837 & .000 \\
\hline Error & 1120.387 & 63 & 17.784 & & \\
\hline Total & 42650.000 & 66 & & & \\
\hline Corrected Total & 6060.364 & 65 & & & \\
\hline
\end{tabular}

a. $\quad$ R Squared $=.815$ (Adjusted R Squared $=.809$ )

Table 6 shows that at the group level, the P significant value of 0.000 is lesser than $\mathrm{P}$ at 0.05 level of significance $(\mathrm{P}<0.05)$. Based on these results, the null hypothesis is therefore rejected. This implies that there was a significant difference in the achievement scores of physics students taught thermal energy using metacognitive scaffolding teaching strategy and those taught using conventional teaching method in favour of those taught using metacognitive scaffolding teaching strategy.

Hypothesis 2: There is no significant difference in the mean achievement scores of male and female physics students taught thermal energy using metacognitive scaffolding teaching strategy.

TABLE 7: ANCOVA Analysis of the Mean Achievement Scores of Male and Female Physics Students taught Using Metacognitive Scaffolding Teaching Strategy

\begin{tabular}{|l|l|l|l|l|l|}
\hline \multicolumn{1}{|c|}{ Source } & $\begin{array}{c}\text { Type III } \\
\text { Sum of } \\
\text { Squares }\end{array}$ & df & $\begin{array}{c}\text { Mean } \\
\text { Square }\end{array}$ & F & Sig. \\
\hline Corrected Model & $3456.654^{\mathrm{a}}$ & 2 & 1768.675 & 154.768 & .000 \\
\hline Intercept & 45.311 & 1 & 43.308 & 36.076 & .004 \\
\hline Pretest & 5543.221 & 1 & 5543.221 & 164.125 & .000 \\
\hline Group & 122.321 & 1 & 121.321 & 10.543 & .100 \\
\hline Error & 450.231 & 63 & 4.309 & & \\
\hline Total & 3568.000 & 66 & & & \\
\hline Corrected Total & 5467.567 & 65 & & & \\
\hline
\end{tabular}

a. $\quad$ R Squared $=.654$ (Adjusted R Squared $=.650$ )

Table 7 shows that at the group level, the $\mathrm{P}$ significant value of 0.100 is greater than $P$ at 0.05 level of significance $(P>0.05)$.The null hypothesis is therefore retained. This implies that there was no significant difference in the achievement scores of male and female physics students taught thermal energy using metacognitive scaffolding teaching strategy. Thus the use of metacognitive scaffolding teaching strategy does not result in sex dependent characteristics.

Hypothesis 3: There is no significant difference in the mean retention scores of physics students taught thermal energy using metacognitive scaffolding teaching strategy and those taught using conventional teaching method.
TABLE 8: ANCOVA Analysis of the Mean Retention Scores of Physics Students Taught Using Metacognitive Scaffolding Teaching Strategy and Conventional Teaching Method

\begin{tabular}{|l|l|l|l|l|l|}
\hline \multicolumn{1}{|c|}{ Source } & $\begin{array}{c}\text { Type III } \\
\text { Sum of } \\
\text { Squares }\end{array}$ & df & $\begin{array}{c}\text { Mean } \\
\text { Square }\end{array}$ & F & Sig. \\
\hline Corrected Model & $5776.327^{\mathrm{a}}$ & 2 & 2888.163 & 465.042 & .000 \\
\hline Intercept & 36.847 & 1 & 36.847 & 5.933 & .018 \\
\hline Pretest & 4854.508 & 1 & 4854.508 & 781.656 & .000 \\
\hline Group & 121.312 & 1 & 121.312 & 19.533 & .000 \\
\hline Error & 391.264 & 63 & 6.211 & & \\
\hline Total & 43467.000 & 66 & & & \\
\hline Corrected Total & 6167.591 & 65 & & & \\
\hline
\end{tabular}

a. R Squared $=.937$ (Adjusted R Squared $=.935$ )

Table 8 shows that at the group level, the $P$ significant value of 0.000 is lesser than $\mathrm{P}$ at 0.05 level of significance $(\mathrm{P}<0.05)$. Based on these results, the null hypothesis is therefore rejected. This implies that there was a significant difference in the retention scores of physics students taught thermal energy using metacognitive scaffolding teaching strategy and those taught using conventional teaching method in favour of the former. Thus, with the use of metacognitive scaffolding teaching strategy in physics, students are most likely to retain more physics concepts than those taught using conventional method of teaching.

Hypothesis 4: There is no significant difference in the mean retention scores of male and female physics students taught thermal energy using metacognitive scaffolding teaching strategy.

TABLE 9: ANCOVA Analysis of the Mean Retention Scores of Male and Female Physics Students taught Using Metacognitive Scaffolding Teaching Strategy

\begin{tabular}{|l|l|l|l|l|l|}
\hline \multicolumn{1}{|c|}{ Source } & $\begin{array}{c}\text { Type III Sum of } \\
\text { Squares }\end{array}$ & df & $\begin{array}{c}\text { Mean } \\
\text { Square }\end{array}$ & \multicolumn{1}{|c|}{ F } & Sig. \\
\hline Corrected Model & $5468.128^{\mathrm{a}}$ & 2 & 2176.145 & 366.023 & .000 \\
\hline Intercept & 28.657 & 1 & 33.756 & 4.9131 & .011 \\
\hline Pretest & 5021.435 & 1 & 4965.498 & 699.159 & .000 \\
\hline Group & 101.987 & 1 & 135.104 & 17.435 & .056 \\
\hline Error & 235.132 & 63 & 4.001 & & \\
\hline Total & 40465.126 & 66 & & & \\
\hline Corrected Total & 6578.639 & 65 & & & \\
\hline
\end{tabular}

a. $\quad$ R Squared $=.911$ (Adjusted R Squared $=.905$ )

Table 9 shows that at the group level, the P significant value of 0.056 is greater than $\mathrm{P}$ at 0.05 level of significance $(\mathrm{P}>0.05)$. The null hypothesis is therefore retained. This implies that there was no significant difference in the retention scores of male and female physics students taught thermal energy using metacognitive scaffolding teaching strategy.

\section{DISCUSSION}

The result from hypothesis 1 showed that physics students had better achievement scores when taught thermal energy using metacognitive scaffolding teaching strategy than their counterpart who were taught using the conventional teaching method. This finding is in agreement with those of Fouche (2013), Jayapraba and Kanmani (2015) and Uzoechi and Gimba (2015) where they reported that metacognitive instructional strategy improved students' achievement compared with those taught using the conventional teaching method. The reason for this finding might be that metacognitive scaffolding teaching strategy helps in improving the quality of instruction and students' innovative thinking skills that might have led to better achievement scores in thermal energy. 
The result from hypothesis 2 showed that male physics students did not perform better than their female counterparts when taught thermal energy using metacognitive scaffolding teaching strategy. The finding disagrees with that of Uzoechi and Gimba (2015) who reported that male physics students had a better achievement scores than their female counterparts using metacognitive explicit teaching method. The difference in their findings with the present study may be that male physics students had a better understanding of physics using explicit teaching method in Uzoechi and Gimba (2015), while the use of three teaching models in the present study enabled female physics students to improve their knowledge. The reason for this finding might be that physics students irrespective of gender difference were able to attain a higher mental thinking level when taught using these three teaching models in metacognitive scaffolding teaching strategy.

The result from hypothesis 3 revealed that physics students had better retention scores when taught thermal energy using metacognitive scaffolding teaching strategy than their counterparts who were taught using the conventional teaching method. This finding agrees with the finding of Adodo (2013) who established that mind mapping metacognitive strategy was more effective in enhancing retention than the conventional teaching method. The reason for this finding might be that students did not understand the lessons when taught using concept mapping and guided discovering as integrated teaching approach.

The result from hypothesis 3 revealed that male physics students did not have better retention scores than their female counterparts when taught thermal energy using metacognitive scaffolding teaching strategy. This finding agrees with the finding of Adodo (2013) which revealed that mind mapping metacognitive strategy improved students' retention irrespective of gender difference. The similarity in their findings might be because both teaching strategies engages students in collaborative thinking which enhances their mental thinking level to retain what they have learnt after a period of time.

\section{CONCLUSION}

Based on the findings of the study, it is concluded that Physics students taught using metacognitive scaffolding teaching strategy have higher achievement scores and retention scores than their counterpart taught using the conventional teaching method. This shows that metacognitive scaffolding teaching strategy is more effective in teaching thermal energy than the use of the conventional teaching method. Also, there is no gender dominance in physics students' achievement and retention when taught using metacognitive scaffolding teaching strategy.

\section{RECOMMENDATIONS}

The study therefore recommends that:

1. Physics teachers should be encouraged to teach physics using metacognitive scaffolding teaching strategy for classroom instruction in both single and coeducational schools.

2. Curriculum planners and developers should consider the introduction of metacognitive scaffolding teaching strategy in senior secondary school physics curriculum.

\section{REFERENCES}

[1] Abosede, M.E. (2010). Gender and socio-economic status as correlates of students' academic achievement in senior secondary school. European Scientific Journal, 8 (4), 23-36.

[2] Adodo, S.O. (2013). Effect of mind-mapping as a self-regulated learning strategy on students' achievement in Basic Science and Technology. Mediterranean Journal of Social Science, 4(6), 163172

[3] Agommuoh, P.C. \& Ifeanacho, A.O.(2013). Secondary school students' assessment of innovative teaching strategies in enhancing achievement in physics and mathematics. IOSR Journal of Research \& Method in Education, Vol. 3, Issue 5 (Nov. -Dec. 2013), 6-11.

[4] Azevedo, R., \& Hadwin, A. F. (2005). Scaffolding selfregulated learning and metacognition: Implications for the design of computer-based scaffolds. Instructional Science, 33 (5\&6), 367-379.

[5] Denton, D.W. (2014). Characteristics of scaffolding and activities for using it in classroom. Washington State Association for Supervision and Curriculum Development

[6] Duyilemi, A.N., Olangunju, A.M., \& Olumide, O.J. (2014). Effect of computer simulation package, gender and parental education on Nigerian secondary school students' attitude towards biology. A paper presented at the 21st Century Academic Forum Conference Proceedings at 2014 Conference at Harvard.

[7] Bello, T.O., \& Oluwatosin, O.B. (2014). Achievement in Physics using mastery learning and mind mapping approaches: Implication on gender and attitude. International Journal of Humanities Social Sciences and Education (IJHSSE),1(12),154-179.

[8] Fouche, J. (2013). The effect of self-regulatory and metacognitive strategy instruction on impoverished students' assessment achievement in physics. A Published Dissertation Presented in Partial Fulfillment of the Requirements for the Degree of Doctor of Education, Liberty University, Lynchburg, VA.

[9] Freeman, S.M. (2013). Effect of the solve strategy on mathematical problem solving skills of secondary students with learning disabilities. A published $P h D$ thesis of the University of North Carolina, Charlotte.

[10] Hall, A. (2015). Instructional scaffolding to improve learning. Spring 2018 Spectrum Newsletter, Faculty Development and Instructional Design Centre, Northern Illinois University.

[11]James, I. \& Okpala, C.O. (2010). The use of metacognitive scaffolding to improve college students' academic success. Journal of College Teaching and Learning, 7(11), 47-50.

[12] Jayapraba, G. \& Kanmani, M. (2015). Effect of metacognitive strategy on jigsaw cooperative learning method to enhance biology achievement. The Online Journal of New Horizons in Education, 4(2), 47-57.

[13] Katcha, M.A. \& Yabogi, N.A. (2015). Science Technology and Mathematics classroom practices. Abuja Journal of Education, 8(1) 197-203.

[14] Lindstrom, C., \& Sharma, M.D. (2011). Teaching physics novices at university: A case for stronger scaffolding. Physics Education Research 7, 10-19.

[15] Many, J. E. (2002). An exhibition and analysis of verbal tapestries: Understanding how scaffolding is woven into the fabric of instructional conversations. Reading Research Quarterly, 37, 376-407.

[16] Merriam-Webster Dictionary (2016). Learners' dictionary. Retrieved November, 15, 2016 from http://learnersdictionary.com/terms-of-use. 
[17] Mustafa, B. (2006). Fostering conceptual change by cognitive conflict based instruction on students' understanding of heat and temperature concepts. Eurasia Journal of Mathematics, Science and Technology Education, 2(2), 43-56.

[18] Nodoushan, M.A.S. (2008). The role of metacognition in the language and teaching profession. I-Manager's Journal on Educational Psychology, 2(1).

[19] Nworgu, L.N. (2012). Metacognitive instructional approaches: Implications for the implementation of senior secondary school biology curriculum. Keffi Journal of Educational Studies, 3(1), 114-125.

[20] Okeke, P.N., Okeke, F.N., \& Akande, S.F. (2008). Senior secondary physics. Ibadan: Macmillan Nigeria Publishers Limited.

[21] Omwirhiren, E.M. (2015). Enhancing academic achievement and retention in senior secondary school chemistry through discussion and lecture methods: A case study of some selected secondary schools. Journals of Education and Practice,6(12), 46-57.

[22] Saage, 0. (2009). Causes of mass failures in mathematics examination among students. A commissioned Paper Presented at Government Secondary School, Karu, Abuja.

[23] Uzoechi, B.C., \& Gimba, M. (2015). Gender difference in achievement among secondary school students taught physics concepts using metacognitive instructional technique. Keffi Journal of Educational Studies, 4(1), 72-75.

[24] WAEC (2016). Executive summary of entries, results and chief examiners' reports on the West African senior school certificate examination. WAEC Headquarter, Lagos.

[25] Wood, W. B., \& Gentile, J. M. (2003). Teaching in a research context. Science Educational Journal, 302:1510. 